\title{
Isolation of Actinomycetes Strains and their Different Levels of Resistance against Antibiotics
}

\author{
Khwaja Salahuddin ${ }^{1 *} \mathbb{D}$, Md. Nizamuddin Ansari² ${ }^{\mathbb{D}}$, Chandan Kumar Singh ${ }^{2}$ (D), \\ Anupama $^{3}\left(\mathbb{D}\right.$, Amit Kumar Jha ${ }^{3}$ (D) Ritisha N. Tatmiya ${ }^{4}(D$ and Syeda Fauzia \\ Farheen Zofair $^{5}$ iD
}

${ }^{1}$ Department of Botany, M.R.M. College, L.N. Mithila University, Darbhanga - 846 004, Bihar, India. ${ }^{2}$ Tissue Culture Lab, University Department of Botany, BRA. Bihar University, Muzaffarpur - 842 001, Bihar, India. ${ }^{3}$ Department of Zoology, MRM College, L.N. Mithila University, Darbhanga - 846 004, Bihar, India. ${ }^{4}$ Department of Biology, Christ College, Saurashtra University, Rajkot - 362 002, Gujarat, India. Interdisciplinary Biotechnology Unit, Aligarh Muslim University, Aligarh,202002, Uttar Pradesh, India.

\begin{abstract}
This study is aimed at isolating and characterizing strains of an actinomycetes from soils. Six strains of actinomycetes were isolated from the riverside, rhizoplane and low land of Muzaffarpur district of Bihar (India). The cultural characterisation revealed the production of diffusible pigments of different colours. Heavy sporulation was noticed in some strains. Out of six strains isolated, four strains such as KS-1, KS-2, KS-3 and KS-4 were found to be mesophilic, and the other two KS-5 and KS- 6 showed thermophilic when subjected to a higher temperature. The antibiotic susceptibilities of these six strains gave the idea about the sensitive and resistance nature based on the zone of inhibition against six antibiotics. Three strains (KS-1, KS-3 and KS-5) were found to be sensitive, whereas KS-2, KS-4 and KS-6 exhibited resistance to the particular antibiotic. The antibiogram of these strains such as KS-2, KS- 4 and KS- 6 clearly showed the different levels of resistance such as constitutive resistance, lethal dose50 and minimal inhibitory concentration within the susceptible range of different antibiotics. CR was found to be maximum (3.5 $\mu \mathrm{gmL}-1)$ in strain KS-4 against tetracycline, the highest lethal dose

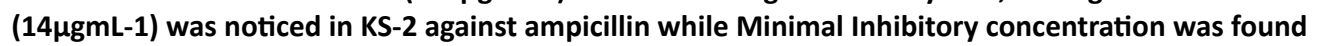

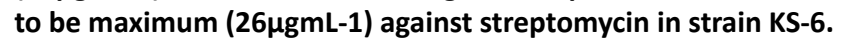

Keywords: Constitutive resistance, Lethal dose, Minimal inhibitory concentration
\end{abstract}

\footnotetext{
*Correspondence: salahuddin212@gmail.com; +91-9668816209
}

(Received: December 30, 2019; accepted: May 05, 2020)

Citation: Salahuddin K, Ansari MN, Singh CK, et al. Isolation of Actinomycetes Strains and their Different Levels of Resistance against Antibiotics. J Pure Appl Microbiol. 2020;14(2):1495-1502. doi: 10.22207/JPAM.14.2.47

(C) The Author(s) 2020. Open Access. This article is distributed under the terms of the Creative Commons Attribution 4.0 International License which permits unrestricted use, sharing, distribution, and reproduction in any medium, provided you give appropriate credit to the original author(s) and the source, provide a link to the Creative Commons license, and indicate if changes were made. 


\section{INTRODUCTION}

Actinomycetes are filamentous Grampositive bacteria with high $\mathrm{G}+\mathrm{C}$ content and are the most widely distributed group of microorganisms in nature which primarily inhabit the soil. The morphology of an actinomycete growing on agar media can provide useful and rapid clues to its identity, but viewing isolated colonies can give little worthwhile information. Morphological characters are still widely used for characterizing genera, for example, the presence or absence of spores on the substrate mycelium or pigment production. The ability to produce motile spores is more widespread in the actinomycetes.

Actinomycetes, a genus of soil microorganisms native to multiple terrains in India, are known to produce antibiotics. As such, these microorganisms must also harbor antibiotic resistance. The microorganisms are quite resistant to the antibiotics that they produce ${ }^{1,2}$. Emerging antibiotic resistance among actinomycetes is of major concern in present times as they cause various diseases in both plants and animals, including human beings. Majority of the antibiotics exhibit constitutive resistance and only some of them show inducible resistance. Inducible resistance can be determined by plasmid genes ${ }^{3}$. Constitutive resistance may be determined by a penicillinase plasmid ${ }^{4}$. Integration of genes coding for constitutive resistance into the chromosome can occur ${ }^{5}$. The involvement of plasmids in the production of antibiotics in Streptomyces has been suggested on many occasions ${ }^{6}$.

In this study, the morphological and antimicrobial characteristics of these strains have been described. The objective of the present investigation was to screen soil samples collected from different localities of Muzaffarpur showing large, diverse and largely unscreened ecosystems for isolation of potent and useful actinomycetes and to ascertain the different levels of resistance against antibiotics.

\section{MATERIAL AND METHODS}

The soil is the most favorable place for the microbial population, especially the actinomycetes. The soil samples were collected from the riverside, rhizoplane of herbaceous plants and low land of Muzaffarpur district of Bihar by digging the soil upto 6-8 inches below the surface. These samples
Table 1. Isolation of Actinomycete strains from soil of three sites

\begin{tabular}{lccc}
\hline Strain & River side & Rhizoplane & Low land \\
\hline KS-1 & + & - & - \\
KS-2 & - & + & - \\
KS-3 & - & - & + \\
KS-4 & + & - & - \\
KS-5 & + & - & - \\
KS-6 & - & + & - \\
\hline
\end{tabular}

Table 2. Morphological features of Actinomycete Strains

\begin{tabular}{lccc}
\hline Strains & $\begin{array}{c}\text { Colour of } \\
\text { Mycelia }\end{array}$ & Pigment & Sporulation \\
\hline KS-1 & White & Absent & Good \\
KS-2 & Cream & Absent & Poor \\
KS-3 & Grey & Grey & Good \\
KS-4 & White & Absent & Poor \\
KS-5 & Brown & Yellowish & Good \\
KS-6 & Brown & Brownish & Good \\
\hline
\end{tabular}

were taken during all seasons. The samples were stored into sterilized polythene bags and taken to the laboratory of University Department of Botany, Muzaffarpur, India $\left(26.1197^{\circ} \mathrm{N}, 85.3910^{\circ}\right.$ E) for further processing. The strains were grown to different media and later exposed for their identification. The strains were later subcultured in both complete and minimal media. Thus isolated strains were purified on selective media for further investigation 7(Table-1).

\section{Composition of media}

Several solid and liquid media were used for isolating the strains of an actinomycetes from different sources. The $\mathrm{pH}$ of the medium was adjusted between 6.8 and 7.2 either by adding $1 \mathrm{~N}$ $\mathrm{NaOH}$ or $1 \mathrm{~N} \mathrm{HCl}$. Then the medium was subjected to autoclaving at $121^{\circ} \mathrm{C}$ for $15 \mathrm{~min}$. Six different media were used for the isolation of actinomycetes strains (Fig.4 and 5).

Soil Extract Agar (SEA)medium consists of $\mathrm{K}_{2} \mathrm{HPO}_{4}-0.4 \mathrm{~g},\left(\mathrm{NH}_{4}\right) 2 \mathrm{HPO}_{4}-0.5 \mathrm{~g}, \mathrm{MgSO}_{4}$. $7 \mathrm{H}_{2} \mathrm{O}-$ $0.05 \mathrm{~g}, \mathrm{MgCl}_{2}-0.01 \mathrm{~g}$, Peptone $-1.0 \mathrm{~g}$, yeast extract $-1.0 \mathrm{~g}$, agar $-15 \mathrm{~g}$ and tap water- $1000 \mathrm{~mL}$.

Actinomycetes Medium (AM) consists of $\left(\mathrm{NH}_{4}\right)_{2} \mathrm{SO}_{4}-1.0 \mathrm{~g}, \mathrm{~K}_{2} \mathrm{HPO}_{4}-1.0 \mathrm{~g}, \mathrm{NaCl}-1.0 \mathrm{~g}, \mathrm{MgSO}_{4}$. $7 \mathrm{H}_{2} \mathrm{O}-1.0 \mathrm{~g}$, starch $-1.0 \mathrm{~g}$, agar-15 g and tap water $1000 \mathrm{~mL}$. 
Table 3. Growth of actinomycete strains on different temperatures

\begin{tabular}{lcccc}
\hline Strains & $30^{\circ} \mathrm{C}$ & $37^{\circ} \mathrm{C}$ & $52^{\circ} \mathrm{C}$ & $60^{\circ} \mathrm{C}$ \\
\hline $\mathrm{KS}-1$ & + & + & - & - \\
$\mathrm{KS}-2$ & + & + & - & - \\
$\mathrm{KS}-3$ & + & + & - & - \\
$\mathrm{KS}-4$ & + & + & - & - \\
$\mathrm{KS}-5$ & - & - & + & + \\
$\mathrm{KS}-6$ & - & - & + & + \\
& & & & \\
$+=$ Growth occurs \\
$-=$ No growth occurs
\end{tabular}

Starch Casein Agar (SCA) medium consists of soluble starch $-1.0 \mathrm{~g}$, Casein $-0.8 \mathrm{~g}, \mathrm{KNO}_{3}-2.0 \mathrm{~g}$, $\mathrm{NaCl}-2.0 \mathrm{~g}, \mathrm{~K}_{2} \mathrm{HPO}_{4}-2.0 \mathrm{~g}, \mathrm{MgSO}_{4} \cdot 7 \mathrm{H}_{2} \mathrm{O}-0.05 \mathrm{~g}$, $\mathrm{CaCO}_{3}-0.02 \mathrm{~g}_{\text {, }} \mathrm{FeSO}_{4} \cdot 7 \mathrm{H}_{2} \mathrm{O}-0.01 \mathrm{~g}$, agar $-15 \mathrm{~g}$ and distilled water $-1000 \mathrm{~mL}$.

Glucose Asparagine Agar (GAA) medium consists of glucose $-1.0 \mathrm{~g}$, asparagine $-0.5 \mathrm{~g}$, $\mathrm{K}_{2} \mathrm{HPO}_{4}-0.5 \mathrm{~g}$, agar $-15 \mathrm{~g}$ and distilled water -1000 $\mathrm{mL}$.

Czapek-Dox Agar (CDA) medium consists of $\mathrm{NaNO}_{3}-2.0 \mathrm{~g}, \mathrm{~K}_{2} \mathrm{HPO}_{4}-1.0 \mathrm{~g}, \mathrm{MgSO}_{4}-0.5 \mathrm{~g}, \mathrm{KCl}-$ $0.5 \mathrm{~g}, \mathrm{FeSO}_{4} 7 \mathrm{H}_{2} \mathrm{O}-0.01 \mathrm{~g}$, sucrose- $30 \mathrm{~g}$, agar- $15 \mathrm{~g}$ and distilled water $-1000 \mathrm{~mL}$.

Starch Agar (SA) medium consists of soluble starch $-2.0 \mathrm{~g}$, peptone $-5.0 \mathrm{~g}$, beef extract $-3.0 \mathrm{~g}$, agar $-15 \mathrm{~g}$ and distilled water $-1000 \mathrm{~mL}$. Normal saline

Normal saline was prepared by dissolving $8.7 \mathrm{~g}$ of $\mathrm{NaCl}$ in one litre of distilled water. A drop of Tween-80 was poured into it. It was then distributed in $15 \mathrm{~mL}$ vial containing $10 \mathrm{~mL}$ of normal saline and then subjected to autoclaving for sterilization.

Serial dilution

A known amount $(10 \mathrm{~g})$ of soil was suspended or agitated in a known volume of sterile water blank ( $9 \mathrm{~mL}$ or so to make the total volume of $10 \mathrm{~mL}$ ) to make a microbial suspension. Serial dilutions, $10^{2} \ldots \ldots .10^{5}$ were made by pipetting measured volumes (usually $1 \mathrm{~mL}$ ) into additional dilution blanks having $9 \mathrm{~mL}$ sterile water. Finally, $0.2 \mathrm{~mL}$ aliquot of various dilutions was added to sterile Petri plates containing $15 \mathrm{~mL}$ of sterile cooled and solid media. These plates were then subjected to incubation at a desirable temperature. The colonies appearing on dilution plates were counted, averaged and multiplied by
Table 4. Antibiotics and their concentrations per filter paper disc

\begin{tabular}{ll}
\hline Antibiotics & Concen. $(\mu \mathrm{g} \mathrm{ml}-1)$ \\
\hline Ampicillin & 10 \\
Gentamicin & 10 \\
Kanamycin & 30 \\
Rifampicin & 30 \\
Streptomycin & 10 \\
Tetracycline & 10 \\
\hline
\end{tabular}

Source: Span Diagnostics Ltd.

Table 5. Antibiotics and zone of inhibition of Actinomycete strains

Isolated Zone of inhibition ( $\mathrm{mm}$ ) after 48 hours strains

\begin{tabular}{lcccccc}
\cline { 2 - 6 } & $\mathrm{A}$ & $\mathrm{G}$ & $\mathrm{K}$ & $\mathrm{R}$ & $\mathrm{S}$ & $\mathrm{T}$ \\
\hline KS-1 & $26 \mathrm{~s}$ & $20 \mathrm{~s}$ & $11 \mathrm{r}$ & $26 \mathrm{~s}$ & $24 \mathrm{~s}$ & $32 \mathrm{~s}$ \\
$\mathrm{KS}-2$ & $11 \mathrm{r}$ & $26 \mathrm{~s}$ & $16 \mathrm{r}$ & $22 \mathrm{~s}$ & $14 \mathrm{r}$ & $35 \mathrm{~s}$ \\
$\mathrm{KS}-3$ & $24 \mathrm{~s}$ & $16 \mathrm{r}$ & $22 \mathrm{~s}$ & $23 \mathrm{~s}$ & $26 \mathrm{~s}$ & $32 \mathrm{~s}$ \\
$\mathrm{KS}-4$ & $16 \mathrm{r}$ & $20 \mathrm{~s}$ & $13 \mathrm{r}$ & $25 \mathrm{~s}$ & $14 \mathrm{r}$ & $30 \mathrm{~s}$ \\
$\mathrm{KS}-5$ & $18 \mathrm{r}$ & $24 \mathrm{~s}$ & $22 \mathrm{~s}$ & $24 \mathrm{~s}$ & $26 \mathrm{~s}$ & $30 \mathrm{~s}$ \\
$\mathrm{KS}-6$ & $12 \mathrm{r}$ & $22 \mathrm{~s}$ & $14 \mathrm{r}$ & $11 \mathrm{r}$ & $24 \mathrm{~s}$ & $10 \mathrm{r}$ \\
\hline
\end{tabular}

$A=$ Ampicillin, $G=$ Gentamicin, $K=$ Kanamycin, $R=$ Rifampicin, $S=$ Streptomycin, $T=$ Tetracycline, $r=$ Resistant, $s=$ Sensitive

the dilution factor to find the number of cells/ spores per gram of the sample (Fig. 1, 2 and 3).

\section{Cultural conditions}

The six isolates were characterized according to International Streptomyces Procedure (ISP). The colors of mycelia and soluble pigment after growing on different media were observed by the naked eyes as well as the magnifying lens. To study the mycelia and its sporulation characteristics, the direct method and inclined coverslip method were used ${ }^{8}$ (Table 2 ).

\section{Auxanography}

Thick spore suspensions from the desired strains were mixed with cooled (45$50{ }^{\circ} \mathrm{C}$ ) molten medium and then poured into sterilized Petri plates. The discs containing the different amounts of antibiotics such as ampicillin, gentamicin, kanamycin, rifampicin, streptomycin and tetracycline were placed at the specified marked position of the plates and then subjected to incubation for $48 \mathrm{~h}$ at $37^{\circ} \mathrm{C}$. The zone of inhibition of these different antibiotics could thus be measured. 


\section{Determination of minimal inhibitory concentration and lethal dose ${ }_{50}$}

Nearly 600-800 spores per plate were plated onto a series of oven-dried SCA plates containing increasing concentration of testedantimicrobial agents. The plates were incubated at $37 \pm 2^{\circ} \mathrm{C}$ for $72 \mathrm{~h}$ and observed for growth. The lowest concentration of the antibiotics preventing clear and visible growth on SCA plates were regarded as minimal inhibitory concentration (MIC).

The susceptibility test was done by serial dilution method. One $\mathrm{mL}$ of inoculum having $10^{4}$ spores in $\mathrm{mL}$ suspension was added to each of the test tubes containing $8 \mathrm{~mL}$ of sterile SCA broth. Several dilutions of drugs were prepared, and $1 \mathrm{~mL}$ of each was added to each of the tubes to get an increasing concentration of antimicrobial agents. The test tubes were incubated at $37 \pm 2{ }^{\circ} \mathrm{C}$ and observed after $72 \mathrm{~h}$. Each tube was screened after $72 \mathrm{~h}$ and the lowest dilution of the drug without any growth of the organism was recorded as MIC. A graph was prepared for the percentage of the bacterial population against the different concentrations of antibacterial agents and thus $50 \%$ of the growth of strains was extrapolated from the graph. This was known as $\mathrm{LD}_{50}$ of the chemical against the strain.

\section{Statistical analysis}

All the data's were statistically analyzed and represented means of three replicates of each factor and all the bars denoted the standard error.

\section{RESULTS AND DISCUSSION}

In this study, only six different actinomycetes isolates were obtained based on cultural characteristics. Several media were screened to grow luxuriantly and observe mycelia formation, pigment production and sporulation. Temperature is one of the important parameters for the growth of actinomycetes strains. Out of six strains, four (KS-1, KS-2, KS-3 and KS-4) grew on $37^{\circ} \mathrm{C}$ and were termed as mesophiles while a few of them (KS-5 and KS-6) thrived on $50^{\circ} \mathrm{C}$ when subjected to a higher temperature and were denoted as thermophiles ${ }^{9}$ (Table 3 ).

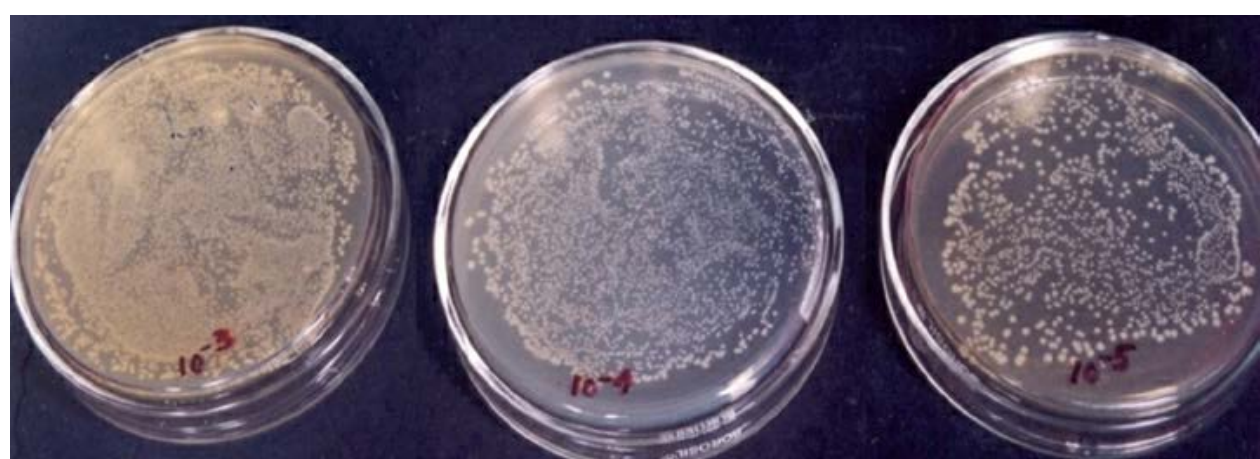

Fig. 1. Culture of actinomycetes strain: Serial dilution method

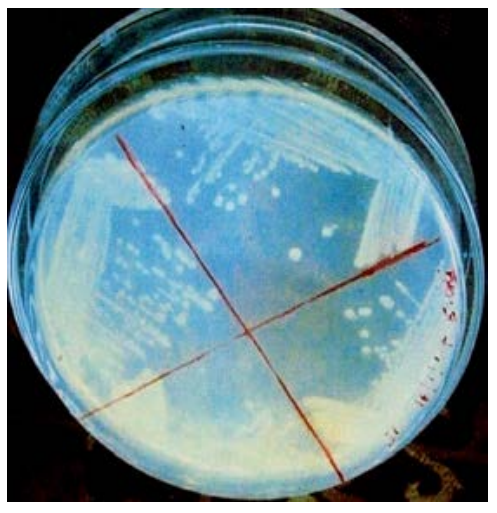

Fig. 2. Isolation of pure colonies of Actinomycetes strain KS-1 (Streaking Method)

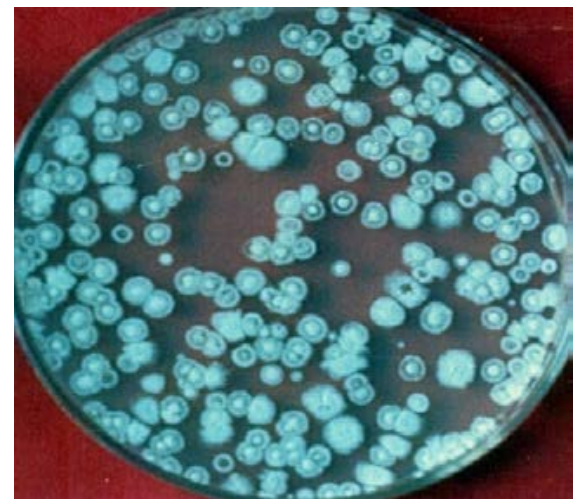

Fig. 3. Colonies of Actinomycetes strain on Czapek-Dox Agar Medium 
The antibiogram of six strains such as KS-1, KS-2, KS-3, KS-4, KS-5 and KS-6, which were isolated from three different areas of soil, revealed the susceptibility of these organisms towards different antibiotics. The antibiotic resistance was not found to be uniform amongst the six strains. This suggests the acquisition of this resistance occurred early in the development of these strains. The low susceptibility of antibiotics could be due to the breakdown of a drug by factors present in the cell or due to defective uptake system ${ }^{10}$.

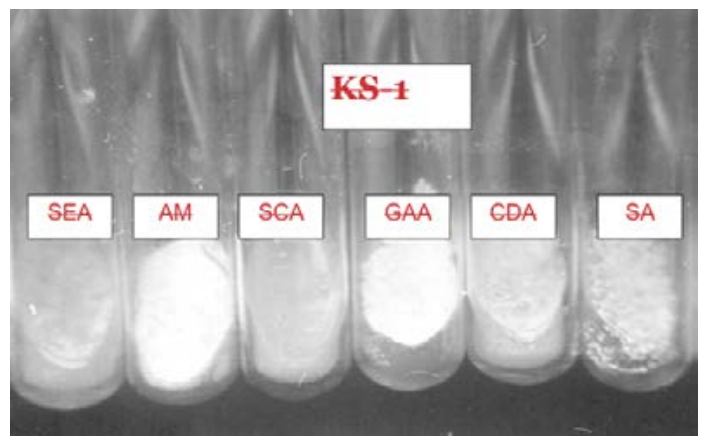

Fig. 4. Culture of Actinomycetes strain KS-1 on different media

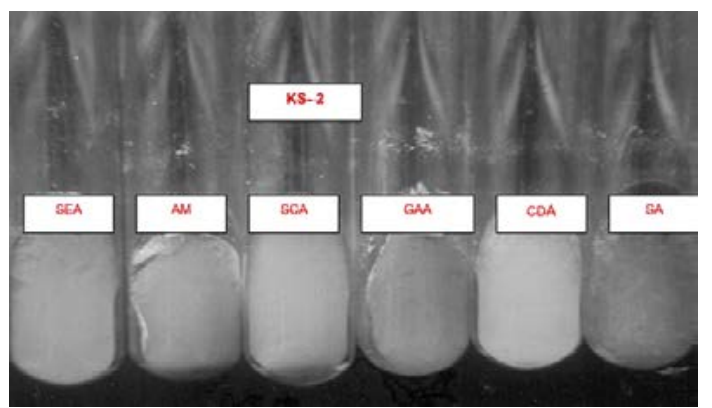

Fig. 5. Culture of Actinomycetes strain KS-2 on different media

The findings suggested that the strain KS-1 showed the resistance against kanamycin only while KS- 2 and KS-4 exhibited a higher level of resistance against ampicillin, kanamycin and streptomycin. Likewise, KS-3 showed sensitive nature against all antibiotics except against gentamycin on which resistance character was revealed. The resistance response of the strain KS-4 was noticed against ampicillin, kanamycin and streptomycin. The strain KS-5 showed resistance nature only against ampicillin, whereas KS-6 exhibited a greater level of resistance against ampicillin, kanamycin, rifampicin and tetracycline (Table 4 and 5)(Fig.6 and 7).
Those strains of actinomycete which did not show growth demonstrated their sensitivity towards the metabolite secreted by actinomycetes, whereas those strains which showed growth exhibited their resistance towards the metabolite. In order to select the potent antibiotic cultures, the strains of actinomycete were cultivated in $100 \mathrm{~mL}$ Erlenmeyer flask containing $30 \mathrm{~mL}$ sterile starch-casein broth. The flask was incubated in a stationary position for $2-7$ days at $30 \pm 2^{\circ} \mathrm{C}$. After incubation, the antibacterial activity of the culture was tested by agar cup plate method. The potency of the organism was measured by showing the degree of inhibition zone. ${ }^{11}$

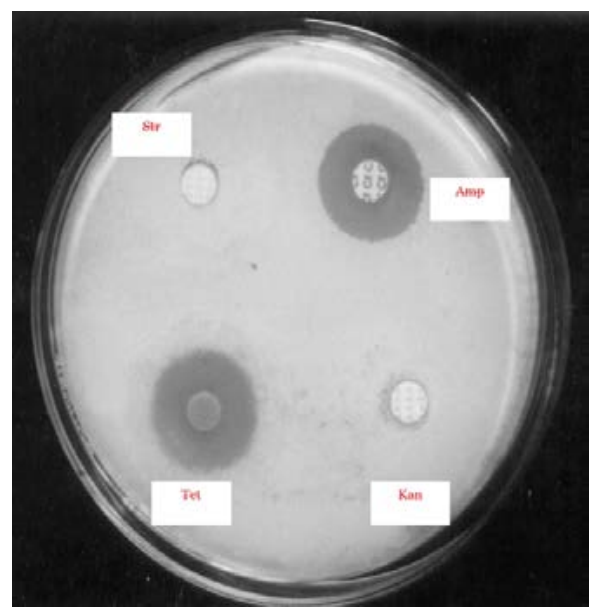

Fig. 6. Inhibitory Zone around different antibiotics on Actinomycetes Strain KS-2

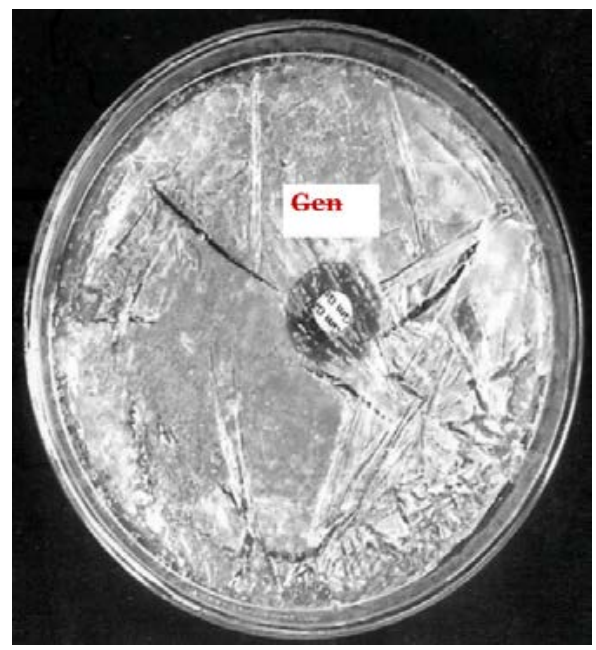

Fig. 7. Inhibitory Zone around gentamycin antibiotic on Actinomycetes Strain KS-2 
All the isolated strains were screened for their resistance profiles to a battery of six antibiotics representing different groups depending upon their mode of action. A strain must be resistant to the antibiotic it produces and it has been shown that multiple resistant genes whose expression is not constitutive confer that resistance in order to fit a maximum to the physiological condition. The perusal established that these strains were found sensitive to most of the antibiotics; however, the level of sensitivity was different in different antibiotics ${ }^{12,13}$. Prolonged usage of antibiotics against microbial infections in inappropriate doses leads to the development of antibiotic resistance which is a recent concern of importance ${ }^{19}$.

The antibiotic resistance was found to be different on a solid medium than on a liquid medium. It is because the rate is always slower on the solid substrate than in liquid shake culture. That is why, the concentration of antibiotics required for either natural resistance (no inhibition) or 50 percent or total inhibition has been found to be more in liquid shake culture than those required for solid culture of Thermoactinomyces vulgaris where the level of antibiotic resistance in liquid medium were two to five times higher than those on solid medium ${ }^{14}$. Since the liquid shake cultures facilitate synchronous growth of mycelia, the accurate and convenient way to monitor the growth profile against antibiotics or curing agents continues to be through liquid culture ${ }^{15}$.

The present investigation was carried out to ascertain the different levels of resistance of antibiotics, i.e., the constitutive resistance (CR) at which there was no inhibition of growth of the strains, $L_{50}$ at which there was $50 \%$ inhibition of growth of the strain and minimal inhibitory concentration (MIC) at which there was complete inhibition of growth of the strains ${ }^{16}$. Minimum inhibitory concentration is important as it indicates as to what level of dilution can be achieved while still retaining the level of activity. The different types of antibiotics were selected for this purpose. The levels of resistance of the antibiotics such as ampicillin, gentamicin, kanamycin, streptomycin, rifampicin and tetracycline were examined against the isolates KS-2, KS-4 and KS-6 which were isolated from the soil of three different sites as mentioned in Material and Methods.
The level of antibiotic resistance for the strains KS-2, KS-4 and KS- 6 was established by determining constitutive resistance (CR), lethal dose (LD) and Minimal Inhibitory Concentration (MIC) of the antibiotics such as ampicillin, gentamicin, kanamycin, rifampicin, streptomycin and tetracycline (Fig.8, 9 and10).

The constitutive resistance for the strain $\mathrm{KS}-2$ was found to be the minimum $\left(0.2 \mu \mathrm{gmL}^{-}\right.$ $\left.{ }^{1}\right)$ and maximum $\left(4 \mu \mathrm{gmL}^{-1}\right)$ for rifampicin and tetracycline, respectively. Similarly, $L_{50}$ of this

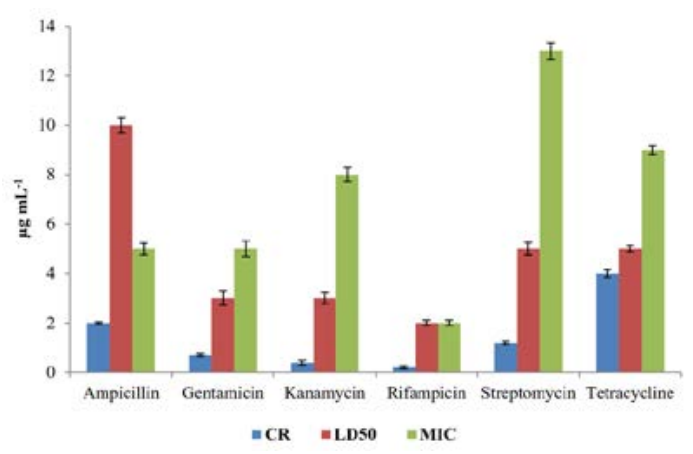

Fig. 8. Level of resistance against different antibiotics in strain KS-2

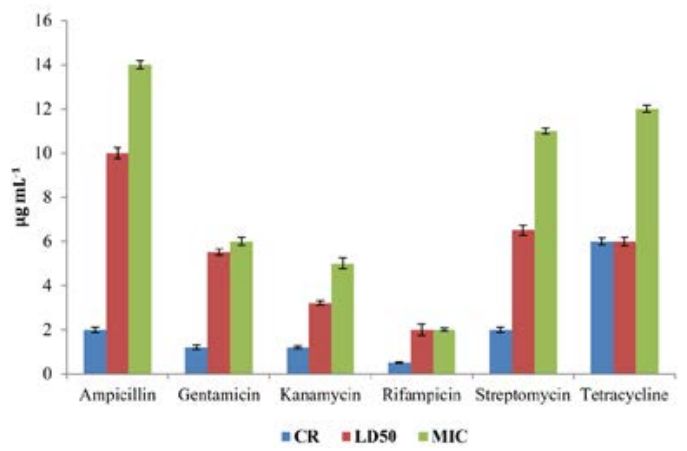

Fig. 9. Levels of resistance against antibiotics in strain KS-4

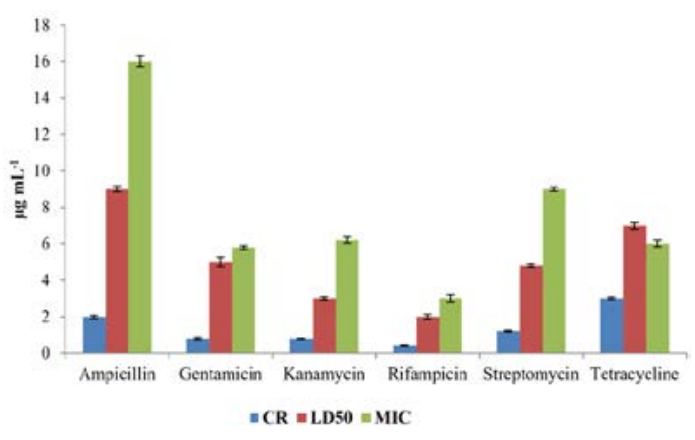

Fig. 10. Level of resistance against antibiotics in strain KS-6 
strain against several antibiotics were observed. It was found to be minimum $\left(1 \mu \mathrm{gmL}^{-1}\right)$ for rifampicin and maximum $\left(10 \mu \mathrm{gmL}^{-1}\right)$ for ampicillin. The minimal inhibitory concentrations of several antibiotics tested on solid media were found to be variable. Thus, the lowest $\left(2 \mu \mathrm{gmL}^{-1}\right)$ and the highest $\left(13 \mu \mathrm{gmL}^{-1}\right)$ concentrations of the tested antibiotics causing inhibition to the growth of strain KS-2 were found to be rifampicin and streptomycin, respectively out of the six antibiotics tested.

The constitutive resistance in case of strain KS-4 was found to be minimum $\left(0.5 \mu \mathrm{gmL}^{-}\right.$ $\left.{ }^{1}\right)$ and maximum $\left(6 \mu \mathrm{gmL}^{-1}\right)$ for rifampicin and tetracycline, respectively. The lethal dose ${ }_{50}$ of this strain was observed to be minimum $\left(2 \mu \mathrm{gmL}^{-1}\right)$ and maximum $\left(10 \mu \mathrm{gmL}^{-1}\right)$ for rifampicin and ampicillin, respectively. The minimal inhibitory concentration of this strain was found to be minimum $(2 \mu \mathrm{gmL}$ $\left.{ }^{1}\right)$ and maximum $\left(12 \mu \mathrm{gmL}^{-1}\right)$ for rifampicin and tetracycline, respectively, out of the six antibiotics tested.

The constitutive resistance of strain KS- 6 was found to be minimum $\left(0.4 \mu \mathrm{gmL}^{-1}\right)$ and maximum $\left(3 \mu \mathrm{gmL}^{-1}\right)$ for rifampicin and tetracycline, respectively. The lethal dose ${ }_{50}$ of this strain was found to be minimum $\left(2 \mu \mathrm{gmL}^{-1}\right)$ and maximum $\left(9 \mu \mathrm{gmL}^{-1}\right)$ for rifampicin and ampicillin, respectively. Similarly, the minimal inhibitory concentration was found to be minimum $\left(3 \mu \mathrm{gmL}^{-}\right.$ $\left.{ }^{1}\right)$ and maximum $\left(16 \mu \mathrm{gmL}^{-1}\right)$ for rifampicin and ampicillin, respectively.

The measure of the zone of inhibition was considered as an important parameter for preliminary screening ${ }^{17}$.The plates for suitable medium were streaked with the strains of actinomycete so that half of the plates were found to have grown with the strain within seven days. The rest part of plates was streaked with different bacterial strains, and such plates were subjected to incubation at $37^{\circ} \mathrm{C}$ within $24 \mathrm{~h}$ and observed.

\section{CONCLUSION}

This study envisaged the different levels of resistance against several antibiotics observed in six isolated strains of Actinomycetes. Most antibiotic resistant actinomycetes develop as a consequence of genetic change. This study revealed the severity of antibiotic resistance which has direct effect on treating infections.
These levels or assays are employed to detect the resistance in Actinomycetes and help understand the molecular mechanisms of the resistance against major antibiotics. In addition, intrinsic and acquired resistance need to be explored in strains of Actinomycetes.

\section{ACKNOWLEDGEMENTS}

The authors fully acknowledge Council of Scientific and Industrial Research (CSIR) for the fund, which made this indispensable study possible. Authors are also grateful to Prof. Arvind Kumar Jha, Principal, MRM College, Darbhanga for his constant encouragement with respect to the publication of this article.

\section{CONFLICT OF INTEREST}

The authors declare that there is no conflict of interest.

\section{FUNDING}

Financial assistance of CSIR in the form of fellowship 09/337(0001)/2002-EMR-1 is gratefully acknowledged.

\section{AUTHORS' CONTRIBUTION}

All authors listed have made a substantial, direct and intellectual contribution to the work, and approved it for publication.

\section{DATA AVAILABILITY}

All data sets obtained or studied during this study are incorporated in the manuscript.

\section{ETHICS STATEMENT}

This article does not contain any studies with human participants or animals performed by any of the authors.

\section{REFERENCES}

1. Ceylan O, Okmen G, Ugar A. Isolation of soil Streptomyces as source of antibiotics active against antibiotic-resistant bacteria, EurAsian J Biosci. 2008;2:73-82

2. Sibanda T, Mabinya LV, Mazomba N, et al. Antibiotic producing potentials of three fresh water actinomycetes isolated from the Eastern Cape Province of South Africa. Int J Mol Sci. 2010;11:2612-2623. https://doi.org/10.3390/ijms11072612

3. Hong $\mathrm{HJ}$, Hutchings JM, Neu GD, Wright $P$, Paget MS, Buttne MJ. Characterization of an inducible vancomycin resistance system in Streptomyces 
coelicolor reveals a novel gene (vanK ) required for drug resistance. Mol Microbiol. 2004;52:1107-1121. https://doi.org/10.1111/j.1365-2958.2004.04032.x

4. Neu LH. The crisis in antibiotic resistance, J Sci. 1992;257(5073):1064-1073. https://doi.org/10.1126/ science.257.5073.1064

5. Hotta K, Yamamoto H, Okami Y, Umezawa H. Resistance mechanism of Streptomyces to aminoglucoside antibiotics. J Antibiot. 1981;34:1175-1182. https:// doi.org/10.7164/antibiotics.34.1175

6. Chopra I, Howa TGB. Bacterial resistance to the tetracycline. Microbiol Rev. 1978;42:707-724. https:// doi.org/10.1128/MMBR.42.4.707-724.1978

7. Athalye M, Lacey J, Goodfellow M. Selective isolation and enumeration of actinomycetes using rifampicin J Appl Bacteriol. 1981;51:289-297. https://doi. org/10.1111/j.1365-2672.1981.tb01244.x

8. Kannika Duangmal, Alan C, Ward, Goodfellow M. Selective isolation of members of the Streptomyces violaceoruber from soil. FEMS Microbiol Lett. 2005;245(2):321-327. https://doi.org/10.1016/j. femsle.2005.03.028

9. Edwards C. Isolation, properties and potential applications of themophilic actinomycetes. Appl Biochem Biotechnol. 1993;42:161-179. https://doi. org/10.1007/BF02788050

10. CLSI (Clinical and LaboratoryStandards Institute) Performancestandards for antimicrobial susceptibility testing. CLSI approved standard M100-S15, 2005; Wayne, PA.

11. Oskay M, Tamer AU, Azeri C. Antibacterial activity of some actinomycetes isolated from farming soils of Turkey. Afr J Biotechnol. 2004;3:441-446. https://doi. org/10.5897/AJB2004.000-2087

12. Ellaiah P, Adinarayana G, Saisha V, Vasu P. An oligoglycosidic antibiotic from a newly isolated
Streptomyces olbovinaceus. Ind J Microbiol. 2005;45:33-36.

13. Selvameenal L, Radakrishnan M, Balagurunathan R. Antibiotic pigment from desert soil actinomycetes; biological activity, purification and chemical screening. Indian J Pharma Sci. 2009;71:499-504.

14. Bauer AW, Kirby WMN, Sherris VC, Turk, M. Antibiotics susceptibility testing by standardized single disc method. Tech Bull Regist Med Technol. 1966;36:49-52.

15. Narayana K J P, Vijyalakshmi M. Cultural, physiological and antimicrobial properties of Streptomyces tenashiensis MTCC 6277. Indian J Microbiol. 2005;45:161-16.

16. EUCAST (European Committee for Antimicrobial Determination of minimum inhibitory concentrations (MICs) of antibacterial agents by broth dilution. Clin Microbiol Infect. 2003;9:1- 7. https://doi.org/10.1046/ j.1469-0691.2003.00790.x

17. Mellouli L, Ben Ameur R, Sioud S, Salem M, Bejar S. Isolation, purification and partial characterization of antibacterial activities produced by a new isolated Streptomyces sp US24 strain. Res Microbiol. 2003;154:345-52. https://doi.org/10.1016/S09232508(03)00077-9

18. Tiwari R, Chakraborty S, Dhama K, Rajagunalen S, Singh SV. Antibiotic resistance-an emerging health problem: Causes, worries, challenges and solution, A review. Int J Curr Res. 2013;5(7):1880-1892.

19. Llor C, Bjerrum L. Antimicrobial resistance: risk associated with antibiotic overuse and initiatives to reduce the problem. Ther Adv Drug Saf. 2014;5(6):229241. https://doi.org/10.1177/2042098614554919

20. Podolsky SH. The evolving response to antibiotic resistance (1945-2018). Palgrave Commun. 2018;4(1):124. https://doi.org/10.1057/s41599-0180181-x 